\title{
DNA damage-related proteins in smokers and non-smokers with oral cancer
}

\author{
Lauren Frenzel SCHUCH(a) (i) \\ José Alcides Almeida DE ARRUDA(a) \\ Karolina Skarlet Silva VIANA(a) (D) \\ Patrícia Carlos CALDEIRA ${ }^{(a)}$ (i) \\ Mauro Henrique Nogueira Guimarães \\ ABREU(b) \\ Vanessa Fátima BERNARDES(c) \\ Maria Cássia Ferreira de AGUIAR(a)
}

(a) Universidade Federal de Minas Gerais UFMG, School of Dentistry, Department of Oral Surgery, Pathology and Clinical Dentistry, Belo Horizonte, MG, Brazil.

(b) Universidade Federal de Minas Gerais UFMG, School of Dentistry, Department of Community and Preventive Dentistry, Belo Horizonte, MG, Brazil.

(c) Universidade Federal de Minas Gerais - UFMG, Biological Sciences Institute, Department of Pathology, Belo Horizonte, MG, Brazil.

Declaration of Interests: The authors certify that they have no commercial or associative interest that represents a conflict of interest in connection with the manuscript.

Corresponding Author:

Vanessa Fátima Bernardes

E-mail: bernardesvf@icb.ufmg.br

hitps://doi.org/10.1590/1807-3107bor-2022.vol36.0027

Submitted: Mar 21, 2021

Accepted for publication: October 10, 2021

Last revision: November 18, 2021
Abstract: Tobacco smoking involves a high risk of human malignancies, including oral cancer, because it contains multiple carcinogens that cause genetic instability. Thus, a worse prognosis would be expected for cancer patients who are smokers. The aim of this study was to assess the DNA damage response through the expression of checkpoint kinase 2 (CHK2), H2A histone family member $\mathrm{X}$ (H2AX), and P53 among smokers and non-smokers with oral squamous cell carcinoma (OSCC). Associations between immunoexpression of proteins and clinicopathological data and histopathological grading were also analyzed. A total of 35 individuals (18 non-smokers and 17 smokers) with OSCC of the tongue and/or floor of the mouth were included. Immunohistochemistry for H2AX was conducted for the identification of double-strand breaks, CHK2, and P53 to evaluate the expression of this protein in cell cycle regulation. The sample consisted of 22 males and 13 females, with a mean age of $63.9 \pm 11.8$ years. OSCC of non-smokers were well-differentiated tumors in $50 \%$ of the cases, and those of smokers were equally distributed into moderately differentiated and poorly differentiated tumors (35.3\% each). Overall, 31 (88.6\%) cases were CHK2-positive, 27 (77.1\%) were H2AX-positive, and 23 (65.7\%) were P53-positive, with no difference between smokers and non-smokers $(\mathrm{p}>0.05)$. No association was found between proteins and clinicopathologic data ( $p>0.05)$. Similarities in CHK2, H2AX, and P53 immunohistochemical staining patterns were observed between smokers and non-smokers, and immunoexpression was not associated with clinicopathological parameters. However, the findings indicated consistent expression of these proteins in OSCC.

Keywords: DNA Damage; Checkpoint Kinase 2; Tumor Suppressor Protein p53; Mouth Neoplasms.

\section{Introduction}

Oral cancer is a global problem with an annual incidence of 377,000 cases. ${ }^{1}$ Oral squamous cell carcinoma (OSCC) is the most common type of oral malignant neoplasia. Genetic, epigenetic and environmental factors are involved in this multifactorial disease. Cigarette smoking is the main etiologic factor of oral cancer, and its mechanism of action involves direct DNA damage. ${ }^{2}$ During carcinogenesis, some pathways 
may be altered, modifying tumor proliferation and apoptosis, and inducing cell transformation and clonal expansion of tumor cells. ${ }^{3}$ DNA damage is a recurrent phenomenon in metabolism that can be induced by exogenous and endogenous agents. When these factors accumulate, they can cause genomic instability, which eventually results in the carcinogenesis process. ${ }^{4}$

Cigarette smoke contains reactive oxidants that may cause macromolecular damage to exposed cells. Thus, the production of reactive oxygen species may damage DNA, occurring in the form of mutations, deletions, changes in sugar bases, cytosine halogenation or oxidation, and methylation. ${ }^{5}$ This fact suggests that levels of specific proteins related to DNA damage such as checkpoint kinase 2 (CHK2), H2A histone family member X (H2AX), and P53 in smokers might serve as a measure of their risk of cancer. ${ }^{6} \mathrm{H} 2 \mathrm{AX}$ is highly conserved and performs critical cellular functions. ${ }^{7}$ The H2AX gene plays an essential role in repairing DNA double strand breaks and in the stability of the genome, being considered a tumor suppressor gene. ${ }^{7,8}$ Meanwhile, CHK2 is involved in the DNA damage repair pathway, capable of activating $P 53$, modulating repair, and blocking the cell cycle.,10 The P53 tumor suppressor gene is essential in regulating cell cycle progression, DNA differentiation, and repair. ${ }^{11}$

The DNA damage response (DDR) is the cell's ability to restore genomic changes caused by endogenous or exogenous mutagens. ${ }^{4} \mathrm{H} 2 \mathrm{AX}$ phosphorylation is a key step in the DDR, playing a role in signaling and initiation of double-strand breaks (DSBs) repair. ${ }^{12}$ DSBs must be repaired quickly and precisely to avoid cell death, chromosomal aberrations, mutations and, in certain cases, initiation of pathological processes such as cancer. The rapid phosphorylation of $\mathrm{H} 2 \mathrm{AX}$ is an early cellular response to DSBs. ${ }^{13}$

In response to DNA damage, a complex signaling network organizes cell cycle checkpoints allowing cell cycle arrest and DNA repair or activating senescence or cell death. ${ }^{14} \mathrm{CHK} 2$ is central to transducing the DNA damage signal and has been implicated in the mediation of both G1/S and G2/M cell cycle arrest in a distinct pathway through P53. ${ }^{15}$ Moreover, P53 is essential in regulating cell cycle progression, differentiation, DNA repair, and apoptosis. Almost $50 \%$ of individuals with oral cancer exhibit P53 gene mutation, which highlights its role as a tumor suppressor. ${ }^{11}$

Nevertheless, the effect of smoking on the expression of CHK2 and H2AX in OSCC has not been well explored. ${ }^{4,5}$ In this study, we evaluated the immunoexpression of CHK2, H2AX, and P53 proteins, which are associated with DNA protection and repair, among smokers and non-smokers with OSCC. Additionally, we analyzed associations of protein levels with clinicopathological data and histopathological grading.

\section{Methodology}

\section{Study design and ethical approval}

This retrospective and cross-sectional study evaluated 35 paraffin-embedded tissue specimens of OSCC. The cases were obtained from the archives of the Oral and Maxillofacial Pathology Laboratory of Universidade Federal de Minas Gerais (UFMG), Belo Horizonte, Brazil. The study was approved by the Institutional Ethics Committee (No. 03012618.1.0000.5149) and the patient's identity remained anonymous according to the Declaration of Helsinki.

\section{Patients and samples}

Individuals with OSCC were analyzed according to sex, age, anatomical location (tongue and/or floor of the mouth), alcohol consumption (yes/no), and smoking habit. Tobacco consumption was determined by the number of cigarettes smoked during the lifetime, and individuals were grouped in two categories as follows: never smokers, with a smoking history of $\leq 0.5$ pack-years, and smokers, with a smoking history of $>10$ pack-years. ${ }^{16}$

Previous studies have compared the levels of proteins in normal mucosa of smokers and nonsmokers. For instance, Zaid et al. ${ }^{17}$ carried out an analysis of P53 in normal epithelium, and nonsmokers had a lower level of positive cells than smokers, (6.6\% and $16.6 \%)$. Zhu et al. ${ }^{18}$ revealed that the expression of $\gamma \mathrm{H} 2 \mathrm{AFX}$ in OSCC was significantly increased compared with normal oral mucosa tissues. 
In the present study, staining of adjacent mucosa was observed in some cases, but as this evaluation was unfeasible in all cases, normal tissue was not accounted for.

The histopathological diagnosis was confirmed by two independent oral and maxillofacial pathologists (V.F.B. and M.C.F.A.), who were blinded to the clinicodemographic data, through the review of the sections stained with hematoxylin and eosin (H\&E) retrieved from the files. Disagreements were jointly reviewed to reach a consensus.

All samples were graded as well differentiated, moderately differentiated, or poorly differentiated according to the World Health Organization criteria. ${ }^{19}$ The exclusion criterion was OSCC individuals submitted to radiotherapy, chemotherapy or other treatments before surgery.

\section{Immunohistochemical staining}

For the immunohistochemical study, 4- $\mu$ m thick sections were obtained from paraffin-embedded tissue blocks and mounted on polarized slides (StarFrost $^{\circledR}$, Waldemar Knittel Glasbearbeitungs $\mathrm{GmbH}$, Braunschweig, Germany). Monoclonal antibodies, including anti-phospho-CHK2 (clone Thr68; Rabbit; Cell Signaling Technology, Danvers, USA; 1:50), anti-phospho-histone H2A.X-Ser139 (clone 20E3; Rabbit; Cell Signaling Technology, Danvers, USA; 1:200), and anti-P53 (clone DO7, Mouse; Dako, Carpinteria, USA; 1:50) were used. The antigenretrieval step was performed using the TRILOGY ${ }^{\mathrm{TM}}$ Concentrate (Cell Marque, Rocklin, USA; 1:100) at a temperature of $96^{\circ} \mathrm{C}$ in a digital water bath (DeLeo, Porto Alegre, Brazil) for 30 minutes. Next, the sections were treated with the EnVision+ Dual Link SystemHRP (Dako, Carpinteria, USA).3.3'-Diaminobenzidine was used as the chromogen (Dako, Carpinteria, USA).

\section{Immunohistochemical assessment}

All cases were evaluated by one observer (L.F.S.) using an eyepiece grid coupled to a light microscope (Zeiss Axiostar, Ser. 48824, Oberkochen, Germany). Immunostaining was evaluated using a semiquantitative analysis of representative regions of each specimen. The slides were analyzed with a light microscope at a final magnification of
$400 \times$. Immunostaining was scored by counting the percentage of cells expressing the abovementioned proteins in at least 10 to 15 different fields. Semi-quantitative analysis was performed based on the proportion of positive neoplastic cells relative to all neoplastic cells in the tissue section. ${ }^{20}$ For each brown unambiguous stain, CHK2 expression was defined as nuclear or cytoplasmic immunoreactivity ${ }^{21}$ and $\mathrm{H} 2 \mathrm{AX}^{4}$ and $\mathrm{P}^{2} 3^{22}$ were defined as nuclear immunoreactivity. Immunoreactivity was considered negative $(0 \%)$, normal $(<50 \%)$, and overexpression $(\geq 50 \%)$, based on the study conducted by Karpathiou et al. (2016). ${ }^{23}$

\section{Data analysis}

Statistical tests were carried out using by the Statistical Package for the Social Sciences (SPSS) software (IBM Corp., version 23.0, Armonk, USA). Outcome data were assessed for normality using the Shapiro-Wilk test for the smoker and non-smoker groups ( $\mathrm{p}<0.05)$. The Mann-Whitney test was used to compare the values of CHK2, H2AX, and P53 proteins according to clinical features (smoking habits, alcohol consumption, and anatomical location). The level of significance was set at $\mathrm{p}<0.05$.

\section{Results}

\section{Demographic and clinicopathological data}

The demographic and clinicopathological characteristics of the sample are shown in Table. Thirty-five OSCC were included. The sample consisted of 22 males (62.8\%) and 13 females (37.2\%), with a male-to-female ratio of 1.7:1. Mean age of the total sample was 63.9 years (range: 47 to $86 \pm 11.8$ years). Of the study subjects, 18 (51.4\%) were non-smokers and $17(48.6 \%)$ were smokers. Among smokers, males $(n=14 / 82.3 \%)$ in the sixth decade of life ( $n=10 / 58.9 \%$ ) were the most affected. Regarding non-smokers, females $(n=10 / 55.6 \%)$ in the eighth decade of life $(n=6 / 33.3 \%)$ were the most affected. Alcohol consumption was reported by $70.6 \%(n=12)$ of smokers and $29.4 \%(n=5)$ of non-smokers.

Of the included cases, symptomatic lesions were present in seven (58.3\%) non-smokers and in four $(66.7 \%)$ smokers. The tongue $(77.8 \%)$ was 
Table. Demographic data and clinicopathological characteristics of the sample.

\begin{tabular}{|c|c|c|}
\hline \multirow{3}{*}{ Variable } & \multicolumn{2}{|c|}{ n (\%) } \\
\hline & $\begin{array}{c}\text { Non-smokers, } \\
\mathrm{n}=18\end{array}$ & $\begin{array}{c}\text { Smokers, } \\
\mathrm{n}=17\end{array}$ \\
\hline & (51.4) & $(48.6)$ \\
\hline \multicolumn{3}{|l|}{ Sex, $n=35$} \\
\hline Male & $8(44.4)$ & $14(82.3)$ \\
\hline Female & $10(55.6)$ & $3(17.7)$ \\
\hline \multicolumn{3}{|l|}{ Age, $n=35$} \\
\hline $40-49$ & $2(11.1)$ & $1(5.9)$ \\
\hline $50-59$ & $4(22.2)$ & $10(58.9)$ \\
\hline $60-69$ & $1(5.6)$ & $6(35.2)$ \\
\hline 70-79 & $6(33.3)$ & - \\
\hline $80-89$ & $5(27.8)$ & - \\
\hline \multicolumn{3}{|l|}{ Alcohol consumption, $n=34$} \\
\hline Yes & $5(29.4)$ & $12(70.6)$ \\
\hline No & $12(70.6)$ & $5(29.4)$ \\
\hline \multicolumn{3}{|l|}{ Symptoms, $n=18$} \\
\hline Yes & 7 (58.3) & $4(66.7)$ \\
\hline No & $5(41.7)$ & 2 (33.3) \\
\hline \multicolumn{3}{|l|}{ Anatomical location, $\mathrm{n}=35$} \\
\hline Tongue & $14(77.8)$ & $7(41.2)$ \\
\hline Floor of the mouth & $3(16.7)$ & $8(47.1)$ \\
\hline Tongue + floor of the mouth & $1(5.5)$ & $2(11.7)$ \\
\hline \multicolumn{3}{|l|}{ Type of sample, $n=35$} \\
\hline Incisional & $12(66.7)$ & $8(47.1)$ \\
\hline Excisional & $6(33.3)$ & $9(52.9)$ \\
\hline \multicolumn{3}{|l|}{ Histology grade, $n=35$} \\
\hline Well-differentiated & $9(50.0)$ & $5(29.4)$ \\
\hline Moderately differentiated & $4(22.2)$ & $6(35.3)$ \\
\hline Poorly differentiated & $5(27.8)$ & $6(35.3)$ \\
\hline
\end{tabular}

the most affected anatomical site in non-smokers, whereas floor of the mouth $(47.1 \%)$ was the main site in smokers.

Regarding histological grading, 40\% ( $\mathrm{n}=14)$ were well-differentiated tumors, $31.4 \%(n=11)$ were moderately differentiated, and $28.6 \%(n=10)$ poorly differentiated. Fifty percent of OSCC in non-smokers were well-differentiated tumors, whereas equal proportions of OSCC were moderately differentiated and poorly differentiated in smokers $(n=6 / 35.3 \%$ each).

\section{Immunoexpression of CHK2, H2AX, and P53 positive cells}

Overall, most cases were positive (normal or overexpression) for CHK2, H2AX, and P53. Thirtyone $(88.6 \%)$ cases were CHK2-positive, 27 (77.2\%) were H2AX-positive, and 23 (65.7\%) were P53-positive. Figure 1 shows the distribution of immunostaining among non-smokers and smokers.

In OSCC samples of smokers, CHK2 staining ranged from 0 to $83.3 \%$ of cells (Figure 2A). One case was negative, six cases were normal, and 10 showed overexpression. The expression in OSCC of nonsmokers was similar (Figure 2B), with expression ranging from 0 to $91.2 \%$. Three cases were negative, seven were normal, and eight showed overexpression.

The expression of $\mathrm{H} 2 \mathrm{AX}$ was also quite similar in smokers (Figure 2C) and non-smokers (Figure 2D). However, disparities in mean number of positive cells were observed between smokers ( 0 to $92.9 \%$ ) and nonsmokers (0 to 53.5\%). Two OSCC of smokers showed H2AX overexpression, 11 showed normal expression, and four were negative. Four OSCC of non-smokers were negative, 11 were considered to have normal expression, and one showed overexpression.

The expression of $\mathrm{P} 53$ positive cells ranged from 0 to $91.9 \%$ in smokers and from 0 to $92.8 \%$ in nonsmokers (Figure 2E and 2F). Six cases of each group were negative, and two cases of each group showed normal staining. Nine cases of smokers and 10 cases of non-smokers were showed overexpression.

No association was found between protein immunoexpression and clinicopathological features of smokers and non-smokers ( $p>0.05$ ). Also, no statistically significant difference was observed between groups (smokers vs. non-smokers) regarding CHK2 ( $p=0.909), H 2 A X(p=0.807)$, and P53 ( $p=$ 0.546 ) proteins (Figure 3 ). No correlation was found among proteins.

\section{Discussion}

Tobacco smoking involves a high risk for human malignancies, including oral cancer, because it contains multiple carcinogens that cause genetic instability. Therefore, a worse prognosis would be expected for cancer patients who are smokers. The 


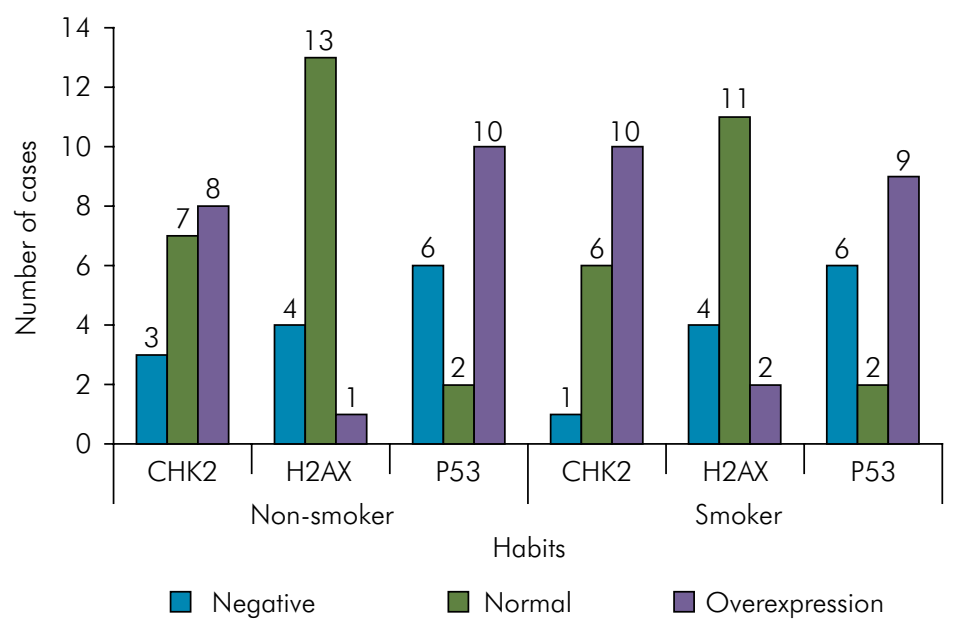

Figure 1. Overall distribution of immunostaining in smokers and non-smokers.

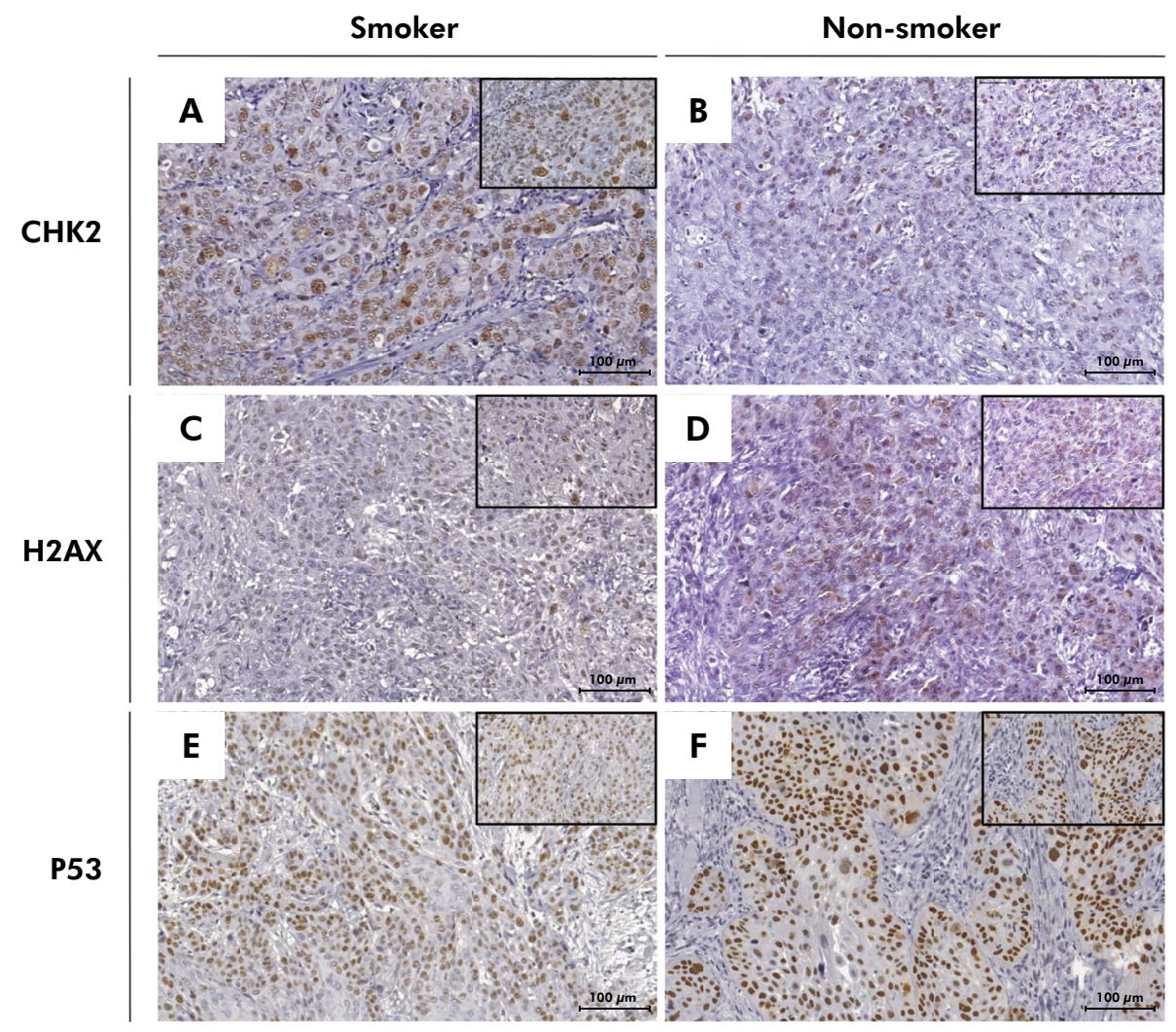

Figure 2. CHK2 staining in a smoker (A) and in a non-smoker (B). H2AX staining in a smoker (C) and in a non-smoker (D). P53 staining in a smoker (E) and in a non-smoker (F). Immunohistochemistry, x 200 and x 400 .

present study investigated the expression of DNA damage-related molecules in smokers and nonsmokers with OSCC. The selected markers participate in different stages of the DNA damage response, from identification of DSBs (H2AX) to induction of cell cycle arrest (CHK2 and P53). The immunoexpression of CHK2, H2AX and P53 was similar in OSCC samples of smokers and non-smokers. Likewise, a previous 

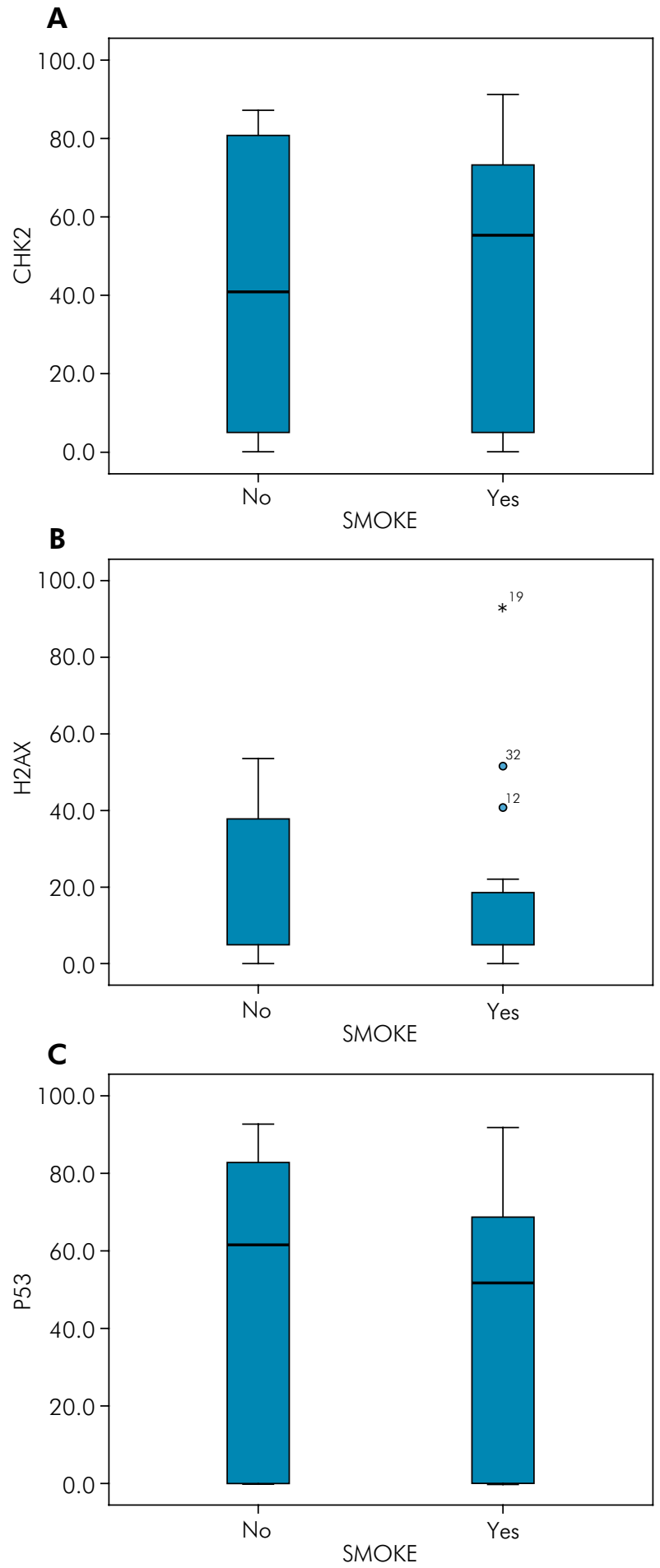

Figure 3. Immunoexpression of the proteins CHK2 $(p=0.909)$, $\operatorname{H2AX}(p=0.807)$ and P53 $(p=0.546)$ between smokers and non-smokers.

study showed similar carcinogenic pathways and outcomes in oral premalignant lesions in smokers and non-smokers. ${ }^{24}$
CHK2 is a key regulator kinase involved in the DNA-damage response-signaling pathway. In this study, although CHK2 expression was slightly lower in non-smokers than in smokers, protein immunoexpression did not differ between the two groups and no other association with clinicopathological features was found. The influence of tobacco on DNA repair and CHK2 action has been demonstrated in other studies. An in vitro investigation showed an attenuation of CHK2 phosphorylation in lung epithelial cells treated with nicotine. ${ }^{25}$ We hypothesized if the similarity between groups could be overridden by a large sample in that study. Accordingly, we performed a posteriori power calculation to identify the power of our sample. In addition, we also performed a simulation of power calculation with 50 cases and 200 cases in each group (https://www.openepi. com/Menu/OE_Menu.htm). Even for these larger samples, the power was maintained below $50 \%$. Therefore, a larger sample would not change our conclusions, i.e., that there is no relevant difference in the expression of these proteins between smokers and non-smokers.

The tumor suppressor P53 has been reported to be another key target of CHK2 in response to DNA damage. P53 changes are mainly caused by exogenous factors, particularly tobacco carcinogens in cases of OSCC. ${ }^{26}$ The frequency of mutations in the P53 gene is higher in lung tumors from smokers than in lung tumors from non-smokers. Additionally, P53 mutations in lung cancer samples from smokers has been observed to be dependent on lifetime cigarette consumption or duration of smoking. ${ }^{27}$ In this work, we focused on protein expression rather than gene mutation. However, we know that almost half of patients with oral cancer have a mutation in the P53 gene, highlighting its role as a tumor suppressor. ${ }^{11}$

Herein, we observed an overexpression of P53 in $19 / 35$ cases $(54.3 \%)$, with no difference between smokers and non-smokers. Other studies have also found a similar expression of P53 in OSCC of smokers and non-smokers. ${ }^{17,24}$ In one study, all specimens were P53-positive, independent of tobacco use. ${ }^{4}$ The authors stated that the main molecular alterations in 
oral premalignant lesions and in lesions associated with progression to OSCC were the same for nonsmokers and smokers and occurred in the early stages of carcinogenesis.

In recent years, the phosphorylated histone $\mathrm{H} 2 \mathrm{AX}$ $(\gamma-\mathrm{H} 2 \mathrm{AX})$ marker has become a robust tool used to monitor DNA DSBs in cancer research and has been suggested to play a potential role in carcinogenesis and early cancer diagnosis. ${ }^{12}$ Accordingly, studies have revealed a correlation between high $\gamma$-H2AX levels and worse prognosis and reduced disease-free survival in breast cancer, ${ }^{28}$ ovarian cancer, ${ }^{29}$ and hepatocellular carcinoma. ${ }^{30}$ Interestingly, an association of H2AXpositive OSCC with reduced overall survival has been reported. ${ }^{31}$ In the present study, no association was observed between clinicopathologic features of smokers and non-smokers and H2AX protein levels. However, a study has reported that the DNA DSB $\gamma$-H2AX marker exists in smoke-exposed placentae, and the cessation of smoking reduces DSB DNA damage to the levels of non-smokers. ${ }^{32}$ In addition, available literature data have demonstrated that exposure of A549 (human lung adenocarcinoma) cells to tobacco smoke or of NHBE (normal human bronchial epithelial) cells to smoke condensate induced $\gamma$-H2AX. ${ }^{33}$

In our study, most non-smokers $(70.6 \%)$ did not drink alcohol and were women in the eighth and ninth decades of life. Indeed, other OSCC series that included non-smokers also reported similar data. ${ }^{34}$ Moreover, some studies that discussed differences in the genetic profile of OSCC of smoker and nonsmokers have been reported elsewhere with divergent results, and the etiopathogenesis of OSCC in the nonsmoking population remains unknown. ${ }^{34}$

While in some studies smoking history did not play a differential role in carcinogenesis, ${ }^{34}$ most studies have reported that smokers are more affected by genetic instability. Although tobacco can cause epigenetic changes in oral epithelial cells, inhibit multiple systemic immune functions of the host, and induce oxidative stress in tissues through its toxic metabolites leading to OSCC, there is no specific mutation signature associating smoking with OSCC. ${ }^{2}$ The mutation signature from smoking appears to be site-specific for lung tumors.
This study has some limitations. The evaluation of tobacco smoking was based on self-reports documented in medical records. Thus, it was not possible to assess the passive smoking of environmental tobacco and other carcinogens to which the patients may have been exposed. Furthermore, we did not consider diet, hormonal status, HPV infection, or second-hand smoking of patients. Thus, the effect of these factors on the immunoexpression of the studied proteins remains to be investigated. Another point that needs to be considered refers to the H2AX range. Although immunohistochemical analysis can be used for this marker, caution should be used when identifying phosphorylated proteins in archival tissues, since immunofluorescence is considered the gold standard. However, due to limited resources, we have decided to maintain this analysis.

\section{Conclusion}

In summary, the present study showed similarities in the CHK2, H2AX and P53 immunohistochemical staining pattern between smokers and non-smokers with OSCC. The results indicated consistent expression of these proteins in OSCC with marked nuclear and/or cytoplasmic labeling. It would be worth investigating if these characteristics persist in non-smokers with poorly differentiated OSCC. This study suggests that it would be interesting to investigate whether DNA damage is a factor involved only in the initial events of carcinogenesis, or whether its presence in advanced stages may contribute to more aggressive tumor behavior and a worse prognosis for the patient.

\section{Acknowledgements}

The authors would like to thank the Coordination for the Improvement of Higher Education Personnel (CAPES, Finance Code 001), Brazil. L.F.S. and J.A.A.A. are the recipients of fellowships. We gratefully acknowledge Prof. Carolina C. Gomes, Department of Pathology, Biological Sciences Institute, Universidade Federal de Minas Gerais, for donating the H2AX antibody. Mrs. Elettra Greene and Katia Muller provided English editing of the manuscript. 
DNA damage-related proteins in smokers and non-smokers with oral cancer

\section{References}

1. Sung H, Ferlay J, Siegel RL, Laversanne M, Soerjomataram I, Jemal A, et al. Global Cancer Statistics 2020: GLOBOCAN Estimates of Incidence and Mortality Worldwide for 36 Cancers in 185 countries. CA Cancer J Clin. 2021 May;71(3):209-49. https://doi.org/10.3322/caac. 21660

2. Jethwa AR, Khariwala SS. Tobacco-related carcinogenesis in head and neck cancer. Cancer Metastasis Rev. 2017 Sep;36(3):411-23. https://doi.org/10.1007/s10555-017-9689-6

3. Monteiro LS, Diniz-Freitas M, Warnakulasuriya S, Garcia-Caballero T, Forteza J, Fraga M. An immunohistochemical score to predict the outcome for oral squamous cell carcinoma. J Oral Pathol Med. 2018 Apr;47(4):375-81. https://doi.org/10.1111/jop.12682

4. Nikitakis NG, Rassidakis GZ, Tasoulas J, Gkouveris I, Kamperos G, Daskalopoulos A, et al. Alterations in the expression of DNA damage response-related molecules in potentially preneoplastic oral epithelial lesions. Oral Surg Oral Med Oral Pathol Oral Radiol. 2018 Jun;125(6):637-49. https://doi.org/10.1016/i.0000.2018.03.006

5. Oliveira SR, Silva IC, Mariz BA, Pereira AM, Oliveira NF. DNA methylation analysis of cancer-related genes in oral epithelial cells of healthy smokers. Arch Oral Biol. 2015 Jun;60(6):825-33. https://doi.org/10.1016/i.archoralbio.2015.02.022

6. Valinluck V, Sowers LC. Inflammation-mediated cytosine damage: a mechanistic link between inflammation and the epigenetic alterations in human cancers. Cancer Res. 2007 Jun;67(12):5583-6. https://doi.org/10.1158/0008-5472.CAN-07-0846

7. Weyemi U, Redon CE, Choudhuri R, Aziz T, Maeda D, Boufraqech M, et al. The histone variant H2A.X is a regulator of the epithelial-mesenchymal transition. Nat Commun. 2016 Feb;7(1):10711. https://doi.org/10.1038/ncomms10711

8. Meador JA, Zhao M, SU Y, Narayan G, Geard CR, Balajee AS. Histone H2AX is a critical factor for cellular protection against DNA alkylating agents. Oncogene. 2008 Sep;27(43):5662-71. https://doi.org/10.1038/onc.2008.187

9. Carrassa L, Damia G. Unleashing Chk1 in cancer therapy. Cell Cycle. 2011 Jul;10(13):2121-8. https://doi.org/10.4161/cc.10.13.16398 PMID:21610326

10. Guffanti F, Fruscio R, Rulli E, Damia G. The impact of DNA damage response gene polymorphisms on therapeutic outcomes in late stage ovarian cancer. Sci Rep. 2016 Dec;6(1):38142. https://doi.org/10.1038/srep38142

11. Sinevici N, O'sullivan J. Oral cancer: deregulated molecular events and their use as biomarkers. Oral Oncol. 2016 Oct;61:12-8. https://doi.org/10.1016/i.oraloncology.2016.07.013

12. Palla VV, Karaolanis G, Katafigiotis I, Anastasiou I, Patapis P, Dimitroulis D, et al. gamma-H2AX: can it be established as a classical cancer prognostic factor? Tumour Biol. 2017 Mar;39(3):1010428317695931. https://doi.org/10.1177/1010428317695931

13. Mah LJ, El-Osta A, Karagiannis TC. gammaH2AX: a sensitive molecular marker of DNA damage and repair. Leukemia. 2010 Apr;24(4):679-86. https://doi.org/10.1038/leu.2010.6

14. Roos WP, Kaina B. DNA damage-induced cell death: from specific DNA lesions to the DNA damage response and apoptosis. Cancer Lett. 2013 May;332(2):237-48. https://doi.org/10.1016/i.canlet.2012.01.007

15. Zannini L, Delia D, Buscemi G. CHK2 kinase in the DNA damage response and beyond. J Mol Cell Biol. 2014 Dec;6(6):442-57. https://doi.org/10.1093/jmcb/mju045

16. Paulin GA, Ouriadov A, Lessard E, Sheikh K, McCormack DG, Parraga G. Noninvasive quantification of alveolar morphometry in elderly never- and ex-smokers. Physiol Rep. 2015 Oct;3(10):e12583. https://doi.org/10.14814/phy2.12583

17. Zaid K, Azar-Maalouf E, Barakat C, Chantiri M. p53 Overexpression in Oral Mucosa in Relation to Shisha Smoking in Syria and Lebanon. Asian Pac J Cancer Prev. 2018 Jul;19(7):1879-82. https://doi.org/10.22034/APJCP.2018.19.7.1879

18. Zhu M, Liu W, Shi L, Xiao X, Wu W, Wu L, et al. Expression of DNA doublestrand repair proteins in oral leukoplakia and the risk of malignant transformation. Oncol Lett. 2018 Jun;15(6):9827-35. https://doi.org/10.3892/ol.2018.8574

19. El-Naggar AK, Chan JK, Grandis JR, Takata T, Slootweg PJ. WHO classification of head and neck tumours. Lyon: IARC Press; 2017.

20. Soares AB, Martinez EF, Ribeiro PF, Barreto IS, Aguiar MC, Furuse C, et al. Factors that may influence polymorphous low-grade adenocarcinoma growth. Virchows Arch. 2017 Apr;470(4):437-43. https://doi.org/10.1007/s00428-017-2085-3

21. Lee HE, Han N, Kim MA, Lee HS, Yang HK, Lee BL, Kim WH. DNA damage response-related proteins in gastric cancer: ATM, Chk2 and p53 expression and their prognostic value. Pathobiology. 2014;81(1):25-35. c10.1159/000351072.

22. Nagao T, Warnakulasuriya S, Sakuma H, Miyabe S, Hasegawa S, Machida J, et al. p53 and ki67 as biomarkers in determining response to chemoprevention for oral leukoplakia. J Oral Pathol Med. 2017 May;46(5):346-52. https://doi.org/10.1111/jop.12498

23. Karpathiou G, Monaya A, Forest F, Froudarakis M, Casteillo F, Marc Dumollard J, et al. p16 and p53 expression status in head and neck squamous cell carcinoma: a correlation with histological, histoprognostic and clinical parameters. Pathology. 2016 Jun;48(4):341-8. https://doi.org/10.1016/i.pathol.2016.01.005

24. Oliva J, Larque AB, Marti C, Bodalo-Torruella M, Nonell L, Nadal A, et al. Oral premalignant lesions of smokers and non-smokers show similar carcinogenic pathways and outcomes: a clinicopathological and molecular comparative analysis. J Oral Pathol Med. 2021Mar;50(3):280-6. https://doi.org/10.1111/jop.12864 
25. Nishioka T, Yamamoto D, Zhu T, Guo J, Kim SH, Chen CY. Nicotine overrides DNA damage-induced G1/S restriction in lung cells. PLoS One. 2011 Apr;6(4):e18619. https://doi.org/10.1371/journal.pone.0018619

26. Hsieh LL, Wang PF, Chen IH, Liao CT, Wang HM, Chen MC, et al. Characteristics of mutations in the p53 gene in oral squamous cell carcinoma associated with betel quid chewing and cigarette smoking in Taiwanese. Carcinogenesis. 2001 Sep;22(9):1497-503. https://doi.org/10.1093/carcin/22.9.1497

27. Takeshima Y, Seyama T, Bennett WP, Akiyama M, Tokuoka S, Inai K, et al. p53 mutations in lung cancers from non-smoking atomic-bomb survivors. Lancet. 1993 Dec;342(8886-8887):1520-1. https://doi.org/10.1016/S0140-6736(05)80087-X

28. Wang B, Zhang Z, Xia S, Jiang M, Wang Y. Expression of $\gamma-\mathrm{H} 2 \mathrm{AX}$ and patient prognosis in breast cancer cohort. J Cell Biochem. 2019 Aug;120(8):12958-65. https://doi.org/10.1002/jcb.28567

29. Mei L, Hu Q, Peng J, Ruan J, Zou J, Huang Q, et al. Phospho-histone H2AX is a diagnostic and prognostic marker for epithelial ovarian cancer. Int J Clin Exp Pathol. 2015 May;8(5):5597-602.

30. Xiao H, Tong R, Ding C, Lv Z, Du C, Peng C, et al. $\gamma$-H2AX promotes hepatocellular carcinoma angiogenesis via EGFR/HIF-1 $\alpha /$ VEGF pathways under hypoxic condition. Oncotarget. 2015 Feb;6(4):2180-92. https://doi.org/10.18632/oncotarget.2942

31. Oliveira-Costa JP, Oliveira LR, Zanetti R, Zanetti JS, Silveira GG, Chavichiolli Buim ME, et al. BRCAl and $\gamma \mathrm{H} 2 \mathrm{AX}$ as independent prognostic markers in oral squamous cell carcinoma. Oncoscience. 2014 Jun;1(5):383-91. https://doi.org/10.18632/oncoscience.47

32. Slatter TL, Park L, Anderson K, Lailai-Tasmania V, Herbison P, Clow W, et al. Smoking during pregnancy causes double-strand DNA break damage to the placenta. Hum Pathol. 2014 Jan;45(1):17-26. https://doi.org/10.1016/i.humpath.2013.07.024

33. Albino AP, Jorgensen ED, Rainey P, Gillman G, Clark TJ, Gietl D, et al. gammaH2AX: a potential DNA damage response biomarker for assessing toxicological risk of tobacco products. Mutat Res. 2009 Aug;678(1):43-52. https://doi.org/10.1016/i.mrgentox.2009.06.009

34. DeAngelis A, Breik O, Koo K, Iseli T, Nastri A, Fua T, et al. Non-smoking, non-drinking elderly females, a 5 year follow-up of a clinically distinct cohort of oral squamous cell carcinoma patients. Oral Oncol. 2018 Nov;86:113-20.

https://doi.org/10.1016/i.oraloncology.2018.09.004 